\title{
PENGARUH STRATEGI PEMBELAJARAN MATHEMATICAL HABITS OF MIND (MHM) TERHADAP KEMAMPUAN PEMECAHAN MASALAH MATEMATIS SISWA SMP
}

\author{
Ratu Sarah Fauziah Iskandar ${ }^{a}$, Duwi Hastuti ${ }^{b}$, Siti Kurniatic \\ a,b,c Program Studi Pendidikan Matematika, Universitas Muhammadiyah Tangerang.

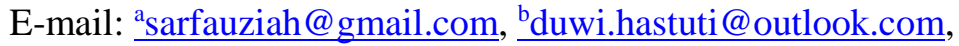 \\ csiti.kurniati14@outlook.com
}

\begin{abstract}
ABSTRAK
Penelitian ini bertujuan untuk mengetahui pengaruh strategi pembelajaran Mathematical Habits of Mind (MHM) terhadap kemampuan pemecahan masalah matematis siswa SMP. Indikator kemampuan pemecahan masalah matematis berdasarkan tahap Polya adalah: (1) Mengetahui apa yang diketahui dan ditanyakan pada masalah (2) Menyederhanakan masalah, mampu membuat eksperimen dan simulasi, mampu mencari subtuju, dan mengurutkan informasi. (3) Mengartikan masalah dalam bentuk kalimat matematika, dan melaksanakan strategi selama proses dan penghitungan berlangsung. (4) Mengecek semua informasi dan penghitungan yang terlibat, mempertimbangkan solusi yang diperoleh logis, melihat alternatif penyelesaian yang lain, membaca pertanyaan kembali, dan bertanya kepada diri sendiri bahwa pertanyaan sudah terjawab. Teknik pengumpulan data yang digunakan adalah tes. Metode yang digunakan dalam penelitian ini adalah metode eksperimen dengan pendekatan kuantitatif. Dalam penelitian ini responden dikelompokan menjadi dua, terdiri dari dua kelas yaitu kelas VII A dan VII B dengan masingmasing kelas 22 siswa. Kelompok pertama adalah kelompok eksperimen, yaitu dengan menggunakan strategi pembelajaran MHM berbasis kemampuan pemecahan masalah. Kelompok kedua adalah kelompok kontrol yaitu dengan menggunakan strategi pembelajaran ekspositori. Pengujian hipotesis menggunakan uji t, hasil perhitungan diperoleh $t_{\text {hitung }} \geq t_{\text {tabel }}$ yaitu 5,702 $\geq$ 2,447 untuk $\alpha=0,05$, maka $\mathrm{H}_{0}$ ditolak. Sehingga diperoleh bahwa ada pengaruh strategi pembelajaran MHM terhadap kemampuan pemecahan masalah matematis siswa SMP.
\end{abstract}

Kata Kunci: MHM (Mathematical Habits Of Mind), Strategi Pembelajaran, Pemecahan Masalah.

\section{THE EFFECT OF MATHEMATICAL HABITS OF MIND (MHM) LEARNING STRATEGY ON MATHEMATICAL SOLVING ABILITY OF SMP STUDENTS}

\begin{abstract}
This study aims to determine the effect of Mathematical Habits of Mind (MHM) learning strategies on the mathematical problem solving abilities of junior high school students. Indicators of mathematical problem-solving abilities based on Polya's stages are: (1) Knowing what is known and asked about the problem (2) Simplify the problem, be able to make experiments and simulations, be able to find sub-goals, and sort information. (3) Interpret the problem in the form of mathematical sentences, and implement the strategy during the process and calculation takes place. (4) Check all the information and calculations involved, consider the solution obtained logically, look at other alternative solutions, read the question again, and ask yourself that the question has been answered. The data collection technique used is a test. The method used in this study is an experimental method with a quantitative approach. In this study respondents were grouped into two, consisting of two classes, namely classes VII A and VII B with 22 class students each. The first group is the experimental group, using the MHM learning strategy based on problem solving abilities. The second group is the control group using expository learning strategies. Hypothesis testing using $t$ test, the calculation results obtained are $t_{\text {hitung }} \geq t_{\text {tabel }} 5.702$ $\geq 2.447$ for $\alpha=0.05$, then $H_{0}$ is rejected. So that it is obtained that there is an influence of MHM learning strategies on the mathematical problem solving ability of junior high school students.
\end{abstract}

Keywords: MHM (Mathematical Habits Of Mind), Learning Strategies, Problem Solving. 


\section{Pendahuluan}

Matematika dapat menimbulkan nilai positif yang harus dimiliki siswa dalam meningkatkan hasil belajar yang baik. Setiawati (2013) mengatakan peranan pembelajaran matematika adalah membentuk siswa yang memiliki kemampuan berpikir tersebut, termasuk dapat mendorong siswa untuk membiasakan diri berpikir atau dikenal dengan Habits of Mind. Hal ini sejalan dengan pendapat Ruseffendi (1991) yang menyatakan "Matematika itu penting sebagai alat bantu, sebagai ilmu (bagi ilmuwan), sebagai pembimbing pola pikir maupun sebagai pembentuk sikap." Untuk itu pola pikir dan kebiasaan berpikir perlu dikembangkan agar menjadi suatu kebiasaan dalam kehidupan sehari-hari terutama kebiasaan dalam belajar. Pemecahan masalah merupakan salah satu aspek yang penting dalam pembelajaran matematika. Menurut Sugiman dkk (2009:1) pembelajaran matematika disekolah seharusnya berfokus pada peningkatan kemampuan siswa dalam memecahkan masalah matematik yang meliputi aspek pengetahuan, konseptual/prosedural, strategi, komunikasi, dan akurasi. Pendapat tersebut juga sejalan dengan Permendiknas Nomor 22 Tahun 2006 tentang Standar Isi Mata Pelajaran Matematika SMP yang menyatakan bahwa ada lima tujuan mata pelajaran matematika yang salah satu dari lima tujuan tersebut adalah agar siswa mampu memecahkan masalah matematika yang meliputi kemampuan memahami masalah, merancang model matematika, menyelesaikan model dan menafsirkan solusi yang diperoleh. Oleh karena itu guru sebagai ujung tombak pembelajaran harus mampu mengelola pembelajaran dan memahami maksud dari pemecahan masalah serta dapat senantisa melatih keterampilannya dalam membantu siswa belajar memecahkan masalah.

\section{Mathematical Habits of Mind} (MHM) adalah suatu strategi yang dapat digunakan dalam pembelajaran, guna membiasakan diri berpikir matematis. Costa dan Kallick (2012) menyebutkan kebiasaan adalah perilaku yang ditunjukkan dengan baik di saat yang tepat. Pembiasaan pengaturan proses berpikir adalah sebuah cara untuk membuka ruang pikiran sebagai tempat proses berpikir berlangsung. Siswa perlu memiliki kebiasaan berpikir yang baik agar mampu meresponsebuah masalah yang muncul dalam pembelajaran. Kebiasaan berpikir siswa dalam pembelajaran menjadi hal yang fundamental ketika mendapat permasalahan yang harus ditemukan solusi penyelesaiannya. Seperti halnya kemampuan pemecahan masalah 
matematis, habits of mindjuga sangat mendukung penampilan siswa dalam kehidupan sehari-hari. Habits of mindmerupakan kekuatan dalam melatih kemampuan siswa dalam menentukan solusi penyelesaian dalam suatu permasalahan.

Millman dan Jacobbe (2010), menawarkan strategi pembelajaran yang lain yaitu strategi Mathematical Habits of Mind (MHM) sebagai strategi untuk mengembangkan kebiasaan berpikir dalam menyelesaikan masalah. Strategi ini meliputi 6 komponen, yaitu: mengeksplorasi ide-ide matematis, merefleksi kesesuaian jawaban dengan masalah, mengidentifikasi strategi pemecahan masalah yang dapat diterapkan, bertanya pada diri sendiri terhadap aktivitas yang telah dilakukan, memformulasi pertanyaan, dan mengkonstruksi contoh. Melalui pengembangan kebiasaan berpikir diatas diharapkan tumbuh sikap teliti, tekun, senang bekerja, berpikir fleksibel, dan rasa percaya diri yang merupakan komponen dari sikap siswa terhadap matematika atau disposisi matematis. Keunggulan kedua pembelajaran ini, memunculkan ide menggabungkan kedua pembelajaran tersebut menjadi strategi MHM terhadap pemecahan masalah matematis siswa SMP. Berdasarkan latar belakang masalah, yang akan dikaji secara mendalam adalah pemecahan masalah matematis siswa SMP dan kebiasaan berpikir (mathematical habits of mind). Dengan demikian rumusan masalah dalam penelitian ini adalah “Apakah terdapat pengaruh antara pembelajaran mathematical habits of mind (MHM) terhadap pemecahan masalah matematis siswa SMP”.

MHM secara matematis adalah suatu strategi yang mengedepankan perilaku berpikir seseorang dalam menyelesaikan persoalan matematika. Kebiasaan-kebiasaan baik yang dilakukan seorang individu akan sangat mempengaruhi hidupnya. Costa dan Kallick (2008) mengidentifikasi enam belas karakteristik kebiasaan berpikir yaitu: (1) Bertahan atau pantang menyerah, (2) Mengatur kata hati, (3) Mendengarkan pendapat orang lain dengan rasa empati, (4) Berpikir luwes, (5) Berpikir metakognitif, (6) Berusaha bekerja teliti dan tepat, (7) Bertanya dan mengajukan masalah secara efektif, (8) Memanfaatkan pengalaman lama untuk membentuk pengetahuan baru, (9) Berpikir dan berkomunikasi secara jelas dan tepat, (10) Memanfaatkan indera dalam mengumpulkan dan mengolah data, (11) Mencipta, berkayal, dan berinovasi, (12) Bersemangat dalam merespons, (13) Berani bertanggung jawab dan menghadapi resiko, (14) 
Humoris, (15) Berpikir saling bergantungan, (16) Belajar berkelanjutan.

Dari pengertian di atas, dapat disimpulkan dalam pembelajaran melalui strategi MHM atau kebiasaan berpikir matematika dapat mendukung siswa untuk memecahkan suatu permasalahan matematis. Selain itu, peserta didik dapat mengidentifikasi strategi pemecahan masalah yang dapat diterapkan untuk menyelesaikan masalah pembelajaran matematika.

Banyak ahli pendidikan matematika menyatakan bahwa masalah merupakan pertanyaan yang harus dijawab atau direspon, namun mereka juga menyatakan bahwa tidak semua pertanyaan otomatis akan menjadi masalah. Hal ini sejalan dengan pendapat Sugiman dkk (2009) yang menyatakan bahwa tidak semua tugas, pekerjaan atau soal yang diberikan kepada siswa dianggap sebagai suatu masalah.

Menurut Schoen Sugiman dkk (2009) masalah berada diantara latihan komputasi (yang strategi solusinya segera diketahui) dan teka-teki (yang tidak mempunyai kondisi strategi solusi yang jelas dan mungkin hanya dimengerti problem solver yang terampil. Akibat dari hal tersebut seseorang yang tidak terampil akan mengalami kesulitan dalam menentukan apakah suatu soal termasuk masalah atau bukan masalah. Maka dari itu beberapa ahli telah membuat ciri- ciri kapan suatu soal dikatakan masalah dan bukan masalah. Bell (1978) menyatakan bahwa suatu situasi merupakan masalah bagi seseorang jika ia menyadari adanya persoalan dalam situasi tersebut, mengetahui bahwa persoalan tersebut perlu diselesaikan, merasa ingin berbuat dan menyelesaikannya, namun tidak dapat dengan segera menyelesaikannya. Berdasarkan para ahli tersebut dapat disimpulkan bahwa masalah merupakan suatu persoalan yang memang harus diselesaikan dengan memberikan suatu solusi yang tepat dalam mengatasinya, terutama di bidang matematika.

Widjajanti (2009) menyatakan bahwa pemecahan masalah adalah proses yang digunakan untuk menyelesaikan masalah. Agar proses pemecahan masalah berjalan dengan baik dibutuhkan suatu strategi pemecahan masalah. Menurut Saad \& Ghani (2008), pemecahan masalah adalah suatu proses terencana yang harus dilakukan supaya mendapatkan penyelesaian tertentu dari sebuah masalah yang mungkin tidak didapat dengan segera. Polya (1973) mendefinisikan bahwa pemecahan masalah sebagai usaha mencari jalan keluar dari suatu kesulitan. Sedangkan menurut Maryam (2013) dalam hasil penelitiannya mengungkapkan bahwa, "dengan adanya proses pemecahan 
masalah merupakan salah satu elemen penting dalam menggabungkan masalah kehidupan nyata". Berdasarkan pendapat tersebut pemecahan masalah adalah usaha mencari jalan keluar untuk menyelesaikan suatu masalah, oleh karena itu penelitian ini disusun agar dapat mengetahui strategi MHM mampu atau tidak dalam menyelesaikan persoalan ini.

Untuk mengukur kemampuan pemecahan masalah siswa peneliti menggunakan indikator kemampuan pemecahan masalah matematis berdasarkan tahap pemecahan masalah Polya yang terlihat pada tabel berikut:

Tabel 1. Indikator Kemampuan Pemecahan Masalah Matematis Berdasarkan Tahap Polya

Tahap Pemecahan
Masalah Oleh
Polya

\begin{tabular}{l|l}
\hline $\begin{array}{l}\text { Memahami } \\
\text { masalah }\end{array}$ & $\begin{array}{l}\text { (1) Mengetahui apa yang diketahui dan ditanyakan pada masalah } \\
\text { dan } \\
\text { (2) Menjelaskan masalah dengan kalimat sendiri. }\end{array}$ \\
\hline Membuat rencana & $\begin{array}{l}\text { (1) Menyederhanakan masalah, } \\
\text { (2) mampu membuat eksperimen dan simulasi, } \\
\text { (3) mampu mencari subtuju, dan } \\
\text { (4) mengurutkan informasi. }\end{array}$ \\
\hline $\begin{array}{l}\text { Melaksanakan } \\
\text { Rencana }\end{array}$ & $\begin{array}{l}\text { (1) Mengartikan masalah dalam bentuk kalimat matematika, dan } \\
\text { (2) melaksanakan strategi selama proses dan penghitungan } \\
\text { berlangsung. }\end{array}$ \\
\hline $\begin{array}{l}\text { Memeriksa } \\
\text { kembali }\end{array}$ & $\begin{array}{l}\text { (1) Mengecek semua informasi dan penghitungan yang terlibat, } \\
\text { (3) melihat alternatif penyelesaian yang lain, (4) membaca } \\
\text { pertanyaan kembali, dan } \\
\text { (5) bertanya kepada diri sendiri bahwa pertanyaan sudah terjawab. }\end{array}$
\end{tabular}

\section{METODE}

Metode yang digunakan dalam penelitian ini adalah metode eksperimen dengan pendekatan kuantitatif. Dalam penelitian ini responden dikelompokan menjadi dua. Kelompok pertama adalah kelompok eksperimen, yaitu dengan menggunakan strategi pembelajaran
MHM berbasis kemampuan pemecahan masalah. Kelompok kedua adalah

kelompok kontrol yaitu dengan menggunakan strategi pembelajaran ekspositori.

$$
\text { Variabel yang diteliti }
$$
menggunakan dua variabel yaitu variabel bebas (X) adalah variabel yang mempengaruhi atau variabel penyebab. Dalam penelitian ini variabel bebasnya 
adalah pengaruh pembelajaran MHM (Mathematical Habits of Mind). Variabel terikat adalah variabel yang tergantung pada variabel bebas. Dalam penelitian ini variabel terikatnya adalah kemampuan pemecahan masalah (Y). Metode ini dipilih sesuai dengan tujuan penelitian dan peneliti ingin mengetahui bagaimanakah pengaruh antara variabel MHM terhadap pemecahan masalah matematika.

Penelitian ini akan dilaksanakan di SMP YAPIS Jakarta Barat pada semester genap tahun akademik 2018/2019. Populasi dalam penelitian ini adalah seluruh peserta didik kelas VII A dan VII B SMP YAPIS Jakarta Barat pada tahun ajaran 2018/2019. Sampel yang dilibatkan dalam penelitian ini adalah sebanyak 68 siswa kelas VII SMP yang tersebar pada dua kelas, yakni kelas eksperimen dan kelas kontrol.

Untuk mendapatkan data pada penelitian ini digunakan instrumen soal pemecahan masalah matematis. Penelitian ini bertujuan untuk melihat pengaruh strategi MHM terhadap pemecahan masalah matematis siswa setelah mendapatkan perlakuan dengan menggunakan strategi MHM. Analisis data yang digunakan meliputi, analisis hasil pretes kelas strategi MHM dan kelas ekspositori untuk melihat pemecahan masalah matematis awal kedua kelas, dan analisis hasil postes kelas strategi MHM dan kelas ekspositori untuk melihat perbedaan pemecahan masalah matematis pada masing-masing kelas.

\section{Hasil Dan Pembahasan}

Data yang diperoleh dalam penelitian ini adalah hasil tes kemampuan pemecahan masalah matematis siswa SMP setelah diajarkan dengan strategi pembelajaran Mathematical Habits of Mind (MHM) pada kelas eksperimen dan model pembelajaran konvensional pada kelas kontrol. Data kemampuan pemecahan masalah matematis siswa ini diperoleh dari nilai tes akhir (posttest). Hasil analisis tes akhir dapat dilihat dari Tabel 2.

Tabel 2. Hasil Analisis deskripsi Posttest

\begin{tabular}{llllll} 
Kelas & $\mathrm{N}$ & $\overline{\boldsymbol{X}}$ & $\mathrm{S}$ & $\boldsymbol{X}_{\max }$ & $\boldsymbol{X}_{\min }$ \\
\hline Eksperimen & 2 & 83,4 & 3,67 & 90 & 54 \\
& 2 & 5 & 4 & & \\
\hline Kontrol & 2 & 75,5 & 5,4 & 87 & 50 \\
& 2 & 5 & & &
\end{tabular}

Keterangan:

$\mathbf{N}=$ banyak siswa

$\overline{\boldsymbol{X}}=$ rata-rata

$\mathbf{S}=$ standar deviasi

$\boldsymbol{X}_{\max }=$ skor tertinggi

$\boldsymbol{X}_{\min }=$ skor terendah

Berdasarkan data pada tabel 1 diketahui bahwa rata-rata nilai matematika untuk kelas eksperimen adalah 83,45 dan 75,55 untuk kelas 
kontrol. Nilai tertinggi siswa di kelas eksperimen adalah 90 dan kelas kontrol 87. Sedangkan nilai terendah untuk kelas eksperimen yaitu 54 dan kelas kontrol yaitu 50. Simpangan baku untuk kelas eksperimen 3,674 dan kelas kontrol 5,4 dengan arti kata bahwa kelas eksperimen mempunyai penyebaran data lebih kecil disbanding kelas kontrol. Dari data diatas dapat dilihat bahwa rata-rata kemampuan pemecahan masalah matematis siswa pada kelas eksperimen lebih tinggi disbanding kelas kontrol. Hal ini berkaitan dengan pembelajaran Mathematical Habits of Mind yang menekankan agar siswa mengkonstruksi pengetahuannya sendiri.

Setelah penelitian dilakukan dan semua data-data yang diperlukan terkumpul, maka data tersebut kemudian dianalisis dengan menggunakan bantuan program IBM SPSS STATISTIC 21. Adapun hasil analisis statistik yang digunakan dalam penelitian ini adalah sebagai berikut :

\section{Uji Normalitas}

Untuk menguji normalitas data kami menggunakan uji kolmogorofsmirnov maupun uji shapiro-wilk dengan hipotesis sebagai berikut:

- nilai signifikasi > 0,05 maka sebaran skor data berdistribusi normal.
- Jika nilai signifikasi < 0,05 maka sebaran skor data tidak berdistribusi normal.

Tabel 3. Uji Normalitas terhadap Nilai Tes Kemampuan Pemecahan Masalah Matematis Siswa SMP

\begin{tabular}{llll} 
Kelas & df & Sig & Ket \\
\hline Eksperimen & 22 & 0,195 & Normal \\
\hline Kontrol & 22 & 0,396 & Normal
\end{tabular}
Berdasarkan tabel 3 diperoleh bahwa nilai signifikansi semua data > 0,05 sehigga dapat disimpulkan bahwa data berdistribusi normal. Perhitungan pengujian persyaratan analisis uji normalitas dibantu dengan program SPSS 21 for windows. Selanjutnya dilakukan uji homogenitas nilai tes pemecahan masalah matematis siswa kelas eksperimen dan kelas kontrol. Hasil pengujian dapat dilihat pada tabel 4 .

Tabel 4. Uji Homogenitas terhadap Nilai Tes Kemampuan Pemecahan Masalah Matematis Siswa SMP

\begin{tabular}{lcccl} 
Kelas & f & f2 & Sig & Ket \\
\hline Eksperimen & 1 & 42 & 0,366 & Homogen \\
\hline Kontrol & 1 & 42 & 0,366 & Homogen \\
\multicolumn{4}{c}{ Berdasarkan } & tabel 4 diperoleh
\end{tabular}
bahwa nilai signifikansi semua data > 0,05, maka dapat disimpulkan data mempunyai variansi yang homogen.

Setelah mencari uji prasyarat analisis, selanjutnya kita cari hipotesis menggunakan uji t. Didapatlah hasil $t_{\text {hitung }}$ dan $t_{\text {tabel }}$ yaitu 5,702 dan 2,447 untuk $\alpha=0,05$. Karena $t_{\text {hitung }} \geq t_{\text {tabel }}$, maka $\mathrm{H}_{0}$ ditolak $\mathrm{H}_{\mathrm{a}}$ diterima. Yang berarti 
ada pengaruh kemampuan pemecahan masalah matematis siswa melalui strategi pembelajaran Mathematical Habits of Pengaruh...(Ratu)

YAPIS.

Elyousif \& Abdelhamied (2013) dan Gordon (2011) menyebutkan bahwa pembelajaran matematika harus dapat mengembangkan habits of mind peserta didik. Oleh karena itu, idealnya habits of mind mahasiswa telah berkembang. Hal ini dikarenakan habits of mind seharusnya telah dilakukan ketika individu berada pada jenjang sekolah pertama, karena mereka berada pada masa transisi dari aritmetika ke aljabar (Mark, Cuoco, Goldenberg, \& Sword, 2010). Berdasarkan temuan Lestari, Kusumah, \& Dewanto (2016) dan Salwah (2014) habits of mind siswa dalam matematika berada pada level pelajar.

\section{Simpulan}

Berdasarkan hasil analisis data penelitian dan pembahasan yang telah diuraikan maka dapat disimpulkan bahwa terdapat pengaruh strategi pembelajaran Mathematical Habits of Mind (MHM) terhadap kemampuan pemecahan masalah matematis siswa SMP.

\section{Pustaka}

Cahyani, H., Setyawati, W.S. 2016. AdMathEdu | Vol.9 No.1| Juni 2019 Kemampuan Pemecahan Masalah melalui PBL untuk Mempersiapkan Generasi Unggul Menghadapi MEA. Seminar Nasional Matematika X, 151-160.

Costa, A. dan Kallick, B. (2008). Describing 16 Habits of Mind. [Online]. Tersedia: http://www.habits-of mind.net/pdf/16HOM2.pdf.

April 2013].

Costa dan Kallick. 2012. Belajar dan memimpin dengan "Kebiasaan pikiran”. Jakarta : Indeks

Elyousif, Y. A. K. \& Abdelhamied, N. E. (2013). Assessing secondary school teachers' performance in developing habits of mind for the students. International Interdisciplinary Journal of Education, 2(2), 168-180.

Gordon, M. (2011). Mathematical habits of mind: Promoting students' thoughtful considerations. Journal of Curriculum Studies, 43(4), 457469. 
https://doi.org/10.1080/00220272.2 011.578664

Khusnul Khotimah. Pengaruh strategi pembelajaran terhadap hasil belajar di tinjjauh dari aktifitas belajar. Surakarta: Tiga Serangkai. 2016.

Mahmudi, A. 2011. Pengaruh Strategi MHM Berbasis Masalah Terhadap Kemampuan Berpikir Kreatif Matematis Dan Persepsi Terhadap Kreativitas. Yogyakarta: Jurnal Cakrawala Pendidikan.

Mark, J, Cuoco, A, Goldenberg, E. P, \& Sword, S. (2010). Developing Mathematical Habits of Mind. Mathematics Teaching in Middle School, 15(9), 505-509.

Maryam Sajadi, Parvaneh Amiripour, Mohsen Rostamy Malkhalifeh. 2013. The Examining Mathematical Word Problems Solving Ability Under Efficient Representation Aspect. International Scientific Publications and Consulting Services. Journal of Mathematics.

Miliyawati, B. 2014. Urgensi Strategi Disposition Habits of Mind Matematis. Infinity Jurnal Ilmiah Program Studi Pendidikan Matematika, 3 (2), 174-188.
Milman, R.S. \& Jacobbe, T. (2010). Fostering Creativity in Preservice Teacher Through Mathematical Habits of Mind. Proceeding of the Discussing Group 9. The $11^{\text {th }}$ International Congress on Mathematical Education. Monterrey, Mexico, July 2012. [Online]. Tersedia: http://dg.icme11.org/document/ get/272. [12 November 2015].

Ruseffendi, H. E. T. 1991. Pengantar Kepada Membantu Guru Mengembangkan Kompetensinya dalam Pengajaran Matematika. Bandung: Tarsito.

Saad, N.S. \& Ghani, A. S. (2008). Teaching Mathematics in Secondary School: Theories and Practices. Perak: Universiti Pendidikan Sultan Idris.

Setiawati, E. 2013. Upaya meningkatkan kemampuan berfikir kreatif matematis melalui bahan ajar dengan strategi habits of mind. https://bdkbandung.kemenag.go.id/i $\underline{\text { ndex.php?option=com_content } \& v i \mathrm{e}}$ $\underline{\mathrm{w}}=$ article \&id=171:upayameningkatkan-kemampuanberpikir-kreatif-matematis-melaluibahan-ajar-dengan-strategi-habitsof-mind \&catid=79\&Itemid=669 
Sugiman, dkk.(2009). Pemecahan Masalah Matematika Dalam Matematika Realistik. Di akses 15 Desember 2016.

Usdiyana, D. (2009). Meningkatkan Kemampuan Berpikir Logis Siswa Sekolah Menengah Pertama melalui Pembelajaran Matematika Realistic. Jurnal Pengajaran MIPA, 1-14.

Wijajanti, D.B. (2009). Kemampuan Pemecahan Masalah Matematis Mahasiswa alon Guru Matematika: Apa dan Bagaimana Mengembangkannya. Disajikan dalam Seminar Nasional FMIPA UNY Tanggal 5 Desember 2009. 